\title{
The Effect of Slow-grown in Vitro Storage Under Different Light Spectra on Banana Plantlets Cv. Prata Catarina (AAB).
}

Paulo Hercilio Viegas Rodrigues ( $\sim$ phrviegas@usp.br)

Universidade de Sao Paulo Escola Superior de Agricultura Luiz de Queiroz https://orcid.org/00000001-7099-0087

\section{Emerson Oliveira}

Fundacao Herminio Ometto - FHO

\section{Christian Demetrio}

ESALQ-USP: Universidade de Sao Paulo Escola Superior de Agricultura Luiz de Queiroz

\section{Guilherme Ambrosano}

ESALQ-USP: Universidade de Sao Paulo Escola Superior de Agricultura Luiz de Queiroz

\section{Sônia Maria Stefano Piedade}

ESALQ-USP: Universidade de Sao Paulo Escola Superior de Agricultura Luiz de Queiroz

\section{Research Article}

Keywords: tissue culture, acclimatization, somaclonal variation, plantlet, LED

Posted Date: June 18th, 2021

DOl: https://doi.org/10.21203/rs.3.rs-597268/v1

License: (c) (i) This work is licensed under a Creative Commons Attribution 4.0 International License. Read Full License 


\section{The effect of slow-grown in vitro storage under different light spectra on banana plantlets cv. Prata Catarina (AAB).}

Paulo HercílioViegas Rodrigues ${ }^{1, *}$, Emerson Luis Oliveira ${ }^{2}$, Christian Aparecido Demetrio ${ }^{1}$, Guilherme Bovi Ambrosano ${ }^{1}$, Sonia Maria Stefano Piedade ${ }^{3}$

1-Luiz de Queiroz College of Agriculture, University of São Paulo, Crop Science Department, Laboratory of Tissue Culture Ornamental Plants, Av. Pádua Dias, 11, Piracicaba, São Paulo, Brasil. CEP: 13400-900 - *phrviegas@usp.br 00000001-7099-0087

2- University of Araras, Herminio Ometto Fundation, Av. Dr. Maximiliano Baruto, 500, Jd. Universitário, Araras, São Paulo, Brasil, CEP: 13607-339

3-Luiz de Queiroz College of Agriculture, University of São Paulo, Statistics Analysis Laboratory, Av. Pádua Dias, 11, Piracicaba, São Paulo, Brasil. CEP: 13400-900

Keywords: tissue culture, acclimatization, somaclonal variation, plantlet, LED

\section{Abstract}

Maintaining updated in vitro plant subcultures is essential for commercial micropropagation and tissue culture research. In unusual situations, the subcultures can be delay and the slow-growth in vitro storage technic could be applied to reduce the loss of plant material. The present study aimed to evaluate the slow-growth in vitro storage of banana plantlets ('Prata Catarina'; group AAB) under different light spectra. Shoot cultures in MS medium without plant growth regulators were maintained under blue (B), red (R), red plus blue (R2B), and white (CW) light spectra $\left(25^{\circ} \mathrm{C} \pm 2^{\circ} \mathrm{C} ; 50 \mu \mathrm{mol} \mathrm{m}^{-2} \mathrm{~s}^{-1}\right)$ for up to 140 days. The plantlets maintained under the R, CW, and R2B spectra did not survive after 140 days of in vitro slow-growth storage. The plantlets maintained under the B spectrum survived after 140 days of in vitro slow-growth storage and showed little browning.

Abbreviations: MS - Murashige and Skoog medium, BA - 6-Benzylaminopurine, CML - Commercial micropropagation laboratory, SGS - Slow grown storage, LS - Light spectra.

In commercial micropropagation laboratories (CML), operational difficulties may arise during commercial micropropagation processes when the in vitro-produced plantlets that are ready to be transplanted cannot be moved to the greenhouse because they are full of unsold plants or because the customer is not ready to receive the plants. Such operational difficulties can result in financial losses to both CMLs and customers (Watt et al. 2000). Recently, many CMLs and tissue culture research centers (TCRC) were temporarily closed due to the COVID-19 pandemic, which reduced the workforce, thereby limiting the subculture frequency during the lockdown. In such unusual situations, CMLs and TCRCs can employ in vitro slow-growth storage (SGS).

During in vitro SGS, to increase the period before subcultures, the development of plants is retarded by suppressing their metabolism, albeit without altering the genetic uniformity and quality of micropropagated plantlets (Kamińska et al. 2016). Culture conditions (temperature, photoperiod, and light intensity) and culture medium components (organic and inorganic nutrients, osmotic, and plant growth regulators) can be adjusted to suppress plant metabolism (Oliveira et al. 2000; Gopal and Chauhan 2010; Kaur et al. 2012; De Carvalho et al. 2014; Thakur et al. 2015).

In the banana germplasm collection at the International Transit Centre (ITC) in Belgium, over 1,600 banana accessions sourced from 38 countries have been maintained under in vitro SGS. At ITC, in vitro SGS is achieved under a combination of low temperature $\left(16^{\circ} \mathrm{C}\right)$ and limited light $\left(25 \mu \mathrm{mol} \mathrm{m}^{-2} \mathrm{~s}^{-1}\right)$ in a growth room (Van den houwe et al. 1995; Panis et al. 2020). Therefore, this method is appropriate to decrease the frequency of subculture by retarding the growth of plantlets, ranging between 3 and 22 months, depending on the genomic group and in vitro browning reaction (Panis et al. 2020). At banana CMLs the limiting of subculture frequency is shorter (around 3-4 weeks). Between 12 and 16 weeks in vitro does not update the subculturing cause severe explant damages. The cytokinin stops working, and the shoots start rooting until consuming all the culture media. In this case, the laborers spend triple times working to cut the roots, and the frequency of contamination increase (Pers. Comm).

To date, few studies have explored different light spectra for in vitro SGS. The use of different light spectra for in vitro SGS of Heliconia champneiana 'Splash' plantlets was evaluated and promising outcomes were achieved using the blue spectrum for up to 12 weeks (Rodrigues et al. 2018). To the best of our knowledge, however, there are no reports on the use of this technique for banana tissue culture. 
To this end, the present study proposes to evaluate the effect for banana in vitro SGS under the different light spectra without compromising plantlet quality.

Fifty shoot tips (ST) were obtained from the uniform sword suckers of 'Prata Catarina' (SCS451; group AAB) with 3-4-month age. The STs were introduced in test tubes (one ST per tube) containing a semi-solid culture medium MS salts and vitamins (Murashige, T.; Skoog, F. 1962) plus $30 \mathrm{~g} \mathrm{~L}^{-1}$ sucrose, $1.0 \mathrm{mg} \mathrm{L}^{-1}$ 6-benzylaminopurine (BA; Sigma-Aldrich), and $2.0 \mathrm{~g} \mathrm{~L}^{-1}$ Phytagel $^{\circledR}$ (Sigma-Aldrich); the $\mathrm{pH}$ of the medium was adjusted to 5.8 before autoclaving for $20 \mathrm{~min}$ at $121^{\circ} \mathrm{C}$. The STs were incubated in a growth room for 30 days at $25^{\circ} \mathrm{C} \pm 2^{\circ} \mathrm{C}$, photoperiod of $14 \mathrm{~h}$; white light was supplied from an LED (6000k, Philips ${ }^{\circledR}$ ) at a photosynthetic photon flux density (PPFD) of $50 \mu \mathrm{mol} \mathrm{m} \mathrm{m}^{-2}$ (LI-250A, LI-COR). Forty healthy STs were induced to multiply under the same conditions as described above, but in jars containing $40 \mathrm{ml}$ of a semi-solid culture medium MS salts and vitamins, plus $30 \mathrm{~g} \mathrm{~L}^{-1}$ sucrose, $3.5 \mathrm{mg} \mathrm{L}^{-1} \mathrm{BA}, 2.0 \mathrm{~g} \mathrm{~L}^{-1} \mathrm{Phytagel}^{\circledR}$, and subculture was performed four times. Few subcultures every 4 weeks ensured the genetic uniformity of the explants (Rodrigues et al, 1998).

Next, 400 in vitro-produced shoots were selected, cut to obtain uniform explants $(1.5 \mathrm{~cm} \times 0.5 \mathrm{~cm})$, and individually inoculated into test tubes $(15.0 \mathrm{~cm} \times 2.5 \mathrm{~cm})$ with a cap $\left(2.5 \mathrm{~cm}\right.$; Kimble $\left.{ }^{\circledR}\right)$ containing $7.0 \mathrm{~mL}$ of the semisolid MS medium as described above but without plant growth regulators. The tubes were incubated under the same conditions as described above but distributed into four light treatments (GreenPower TLED ${ }^{\circledR}$; Philips ${ }^{\circledR}$ ): $\mathrm{R}=100 \%$ red light $(645-675 \mathrm{~nm}) ; \mathrm{B}=100 \%$ blue light $(450-465 \mathrm{~nm}) ; \mathrm{R} 2 \mathrm{~B}=70 \%$ red $+30 \%$ blue light; and $\mathrm{CW}=$ white control (6000k, Philips $\left.{ }^{\circledR}\right)$; the PPFD for all treatments was set at $50 \mu \mathrm{mol} \mathrm{m}^{-2} \mathrm{~s}^{-1}$. In each treatment, the test tubes were centered and equidistantly arranged to ensure uniform light incidence.

Each light treatment included 100 explants, divided into five-time intervals with 20 explants per interval (I1, I2, I3, I4, and I5) without subculture. Every $28 \mathrm{~d}, 20$ plantlets from each treatment were evaluated for survival, height (from the base of the pseudostem to the cigar leaf tip, $\mathrm{cm}$ ), fresh weight (g), pseudostem diameter immediately above the original cut $(\mathrm{cm})$, number of leaves, number of primary roots, the longest root length $(\mathrm{cm})$, and chlorophyll content (expressed as the SPAD index) of the third leaf from the top downward, measured using the CFL1030- chlorophyll meter $\left(\right.$ Falker $\left.^{\circledR}\right)$.

In vitro-stored plantlets evaluated at the indicated time points under each treatment were acclimatized in separate 24-cell plastic trays $\left(163 \mathrm{~cm}^{3}\right)$ containing a commercial horticulture substrate- $\mathrm{BASE}^{\circledR}(50 \%$ pine bark, $30 \%$ fibrous peat, and $20 \%$ vermiculite). The trays were arranged on $0.90 \mathrm{~m}$ high benches and centered in a greenhouse with fogging under $80 \%-90 \%$ humidity and $50 \%$ shading (Aluminet ${ }^{\circledR}$ ). The temperature was maintained at $28^{\circ} \mathrm{C} \pm$ $2^{\circ} \mathrm{C}$ during the 28 days acclimatization period. During this period, the plantlets were evaluated for monitored survival, plantlet height $(\mathrm{cm})$, pseudostem diameter $(\mathrm{cm})$, and leaf number.

During in vitro SGS, and acclimatization period, the experimental design was completely randomized, with plots representing the light treatments and subplots representing the time intervals. All data were subjected to analysis $(F$ test) of variance in the split-plot arrangement, and the mean values among treatments and across time intervals were compared with Tukey's test at $5 \%$ significance.

During SGS, there was an interaction between plant height and light spectrum $(\mathrm{p}=0.0359)$ (Fig. 1a). The cigar leaf length of explants increased steadily up to I4 but decreased during I5 (Fig. 2c). The height of explants grown under different light spectra was in the order $\mathrm{B}<\mathrm{R} 2 \mathrm{~B}<\mathrm{CW}<\mathrm{R}$ (from the shortest to tallest) across time intervals (Fig. 1a).

During SGS, the different light spectra affected leaf number $(\mathrm{p}=0.0005)$ and pseudostem thickness $(\mathrm{p}=$ 0.0285). These characteristics steadily increased until I5 (Fig. $1 \mathrm{~b}$ and 1c). No symptoms of leaf senescence were observed under any light spectrum at I5 (Fig. 2a). The different light spectra affected fresh weight ( $<<0.0001$ ). During the experimental period, fresh weight was the lowest under the B spectrum, and the value fluctuated under the $\mathrm{R}$ spectrum during I4. In contrast, fresh weight was the highest under the CW and R2B spectra from I2 to I5 (Fig. 1d).

During SGS, there was an interaction between root number and light spectrum $(\mathrm{p}<0.0001)$. During $\mathrm{I} 2$, there was a significant increase in growth under the R2B spectrum compared with that under the remaining spectra (Fig. 1d). The number of primary roots increased from I2 to I4 under all evaluated spectra, except R2B.

There were significant differences in evaluated root number under the $\mathrm{CW}$ and other spectra during $\mathrm{I} 3$ and I4. During I5, primary root number under the $\mathrm{CW}$ spectrum and growth under the R2B and R spectra were significantly reduced, but the values were stable under the $\mathrm{B}$ spectrum. Of note, under the $\mathrm{CW}$ spectrum, primary root number increased from I2 to I4 but decreased during I5.

There was a significant interaction between the length of the longest root (Fig. 1e) and the light spectrum ( $\mathrm{p}$ $<0.0001$ ). This length increased from I1 to I4 under all spectra, except CW. Under the CW spectrum, there was a significant reduction in this length from I2 to I 3 and a further significant reduction from I 3 to I4, and the values were lower than those under all the remaining spectra. During I5, there were significant reductions in the length of the longest root under the R, B, and R2B spectra, but the values were stable under the CW spectrum. The roots suffered 
112

113

114

115

116

117

118

119

120

121

122

123

124

125

126

127

128

129

130

131

132

133

134

135

136

137

138

139

140

141

142

143

144

145

146

147

148

149

150

151

152

153

154

155

156

157

158

159

160

161

162

163

164

165

166

167

the effect of in vitro senescence over time, in the order of $\mathrm{CW}>\mathrm{R} 2 \mathrm{~B}>\mathrm{R}>\mathrm{B}$. Under the $\mathrm{B}$ spectrum, characteristic young root color was observed even after 140 days of in vitro SGS (Fig. 2a and red rectangle in 2b). Although we did not quantify the consumption of the culture medium, a larger volume of the culture medium, which was colorless/translucent even during I5, was remaining under the B spectrum.

All plants survived SGS until I4 (Fig. 1g). The explants were grown under the CW, R2B, and R spectra died soon after removal from the test tubes. Excessive browning resulted in the death of some explants. At the intersection of the pseudostem and root, tissue breakage occurred during explant wash, subsequently leading to death, under the $\mathrm{R}$ (1 explant), R2B (1 explant), and CW (2 explants) spectra. No explant loss occurred under the B spectrum.

There was a significant interaction between the SPAD index and the light spectrum $(\mathrm{p}<0.0001)$. The trends were similar under the $\mathrm{CW}, \mathrm{R} 2 \mathrm{~B}$, and $\mathrm{B}$ spectra, with a lower index recorded under $\mathrm{B}$; the opposite trends were observed during I1 and I2, but they remained stable from I3 to I5 (Fig. 1h).

Following SGS, all transplanted plantlets survived the acclimatization period. During SGS, light spectrum affected plantlet height $(\mathrm{p}=0.0181)$, leaf number $(\mathrm{p}=0.0053)$, and pseudostem diameter $(\mathrm{p}<0.0001)$. Plant height and leaf number increased from I1 to I4. During I5 (Fig. 2d), plants grown under the R and B spectra showed reduced development. The fewest leaves (Fig. 3a), the shortest plants (Fig. 3b), and the smallest pseudostem diameter (Fig. 3c) were observed under the R and B spectra (Supplementary Figure 3).

The present study demonstrated that different light spectra affected all evaluated parameters during in vitro SGS. Regarding plantlet height, there was a reduction from I4 to I5 under all spectra, which was caused by the shortening of the cigar leaf. In a previous study, the effects of the B and R spectra and their different combinations during in vitro cultivation Musa paradisiac 'Nam Dinh' were assessed using a sugar-free technique with $\mathrm{CO}_{2}$ injection (Nhut et al. 2002). In that study, the plant height was in the order of B < PGF (fluorescent lamp) < R2B (70\% red + $30 \%$ blue) $<\mathrm{R}$ (from the shortest to tallest). These results were similar to those for 'Prata Catarina' under 140 days of SGS in the present study $(\mathrm{B}<\mathrm{CW}<\mathrm{R} 2 \mathrm{~B}<\mathrm{R})$ as well as for $H$. champneiana 'Splash' under 84 days of in vitro culture under different light spectra (Rodrigues et al. 2018).

Similar trends were observed for fresh weight, which was lower under the B spectrum, for 'Prata Catarina', 'Nam Dinh', and H. champneiana 'Splash'. Thus, different species exhibited similar behaviors during SGS under different light spectra. The plantlets were shorter and showed a lower fresh weight under the B spectrum. Leaf number and explant diameter were not affected by light spectrum during SGS in the present study.

In the plantlets, no yellowing or leaf necrosis, a typical symptom of in vitro stress caused by the gas-saturated in vitro environment and/or nutrient shortage in the culture medium, was observed (Rodrigues et al. 2018); Pimenta et al. 2013). In a restricted environment without regular subculture, gas accumulation due to explant growth can be detrimental to plant development in vitro. Ethylene is one of the gases that significantly affect different physiological processes. Numerous studies have demonstrated the involvement of ethylene in callus proliferation, somatic embryogenesis, and rhizogenesis (Buddendorf-Joosten and Woltering 1996; Biddington 1992; Marota et al. 2001). In H. champneiana 'Splash', leaf senescence was observed under the CW, R2B, and R spectra after 84 days of SGS. The leaves showed discoloration and necrosis, which are typical symptoms of long-term in vitro growth (Rodrigues et al. 2018). In the present study, even under the conditions of restricted gaseous exchange, the 'Prata Catarina' explants were not affected by SGS under different light spectra.

Under in vitro conditions from I 2 to $\mathrm{I} 4$, root growth was suppressed under the $\mathrm{CW}$ spectrum but compensated for by the formation of more primary roots. A similar result was observed, albeit to a lesser extent, under the R2B and $\mathrm{R}$ spectra. During the explant wash for data collection, browning of the tissues at the root tips was observed, which prevented further growth from I3 onward. Meanwhile, this favored an increase in the number of primary roots under these treatments. During I5, the degree of browning in the roots was higher, which results in the death of some explants under the $\mathrm{CW}, \mathrm{R} 2 \mathrm{~B}$, and R spectra. Under the B spectrum, root development was stable, and no symptoms of senescence were observed until I5. The browning of plant tissues is caused by the oxidation of tannins and polyphenols and the formation of highly reactive and toxic quinones. This process can start due to successive subcultures, cuts that generate injuries, or senescence of plant tissues in vitro (Ahmad et al. 2013). Marked root senescence during I5 under the CW, R, and R2B spectra, with the loss of some plantlets, limits the use of these light spectra for 140 days in vitro.

Plantlets grown under the B spectrum showed greater tolerance of the in vitro environment for 140 days, indicating that a longer period in SGS under this is feasible. The culture medium under the B spectrum remained translucent without the darkening effect observed in the other treatments. Darkening of the culture medium occurs as a result of the oxidation of polyphenol exudates from the roots. The absence of this effect under the B spectrum suggests that blue light, directly or indirectly, inhibits the oxidation of tannins and polyphenols from root exudates in vitro.

The effect of light quality on the cellular redox balance in vitro has been poorly studied and is restricted to only a few species (Dutta Gupta 2017). A previous study evaluated the antioxidant capacity in Rehmannia glutinosa 
grown in vitro under different light conditions; the highest total antioxidant capacity of the leaf and root extracts was observed in the presence of blue light (Manivannan et al. 2015). At ITC, some banana accessions did not achieve satisfactory development during SGS, and there may be large differences in subculture conditions such as transfer interval, ranging between 3 and 22 months (Panis et al. 2020). The browning effect during in vitro banana culture varies among different genomic groups and even within the same subgroup (Van den houwe et al. 1995). The prevention of root browning during SGS under blue light is an important result, which may contribute to controlling browning during banana tissue culture.

The lowest SPAD index was observed from I2 to I5 under the B spectrum, indicating lower photosynthetic activity and, consequently, lower metabolic activity during SGS. These results are similar to those reported previously for 'Nam Dinh', in which blue light completely inhibited plantlet growth (Nhut et al. 2002).

The acclimatized plants showed no morphological variation. In the present study, plants under the B spectrum showed reduced growth during I5 of the acclimatization period. In a previous study, no differences in the height, fresh weight, or SPAD index of acclimatized 'Nam Dinh' plants propagated in vitro in PGF under $80 \%$ red $+20 \%$ blue light were observed (Nhut et al. 2002). The results of the present study are unprecedented and demonstrate that prolonged in vitro environmental conditions affect plant development during the acclimatization period.

Factors related to in vitro culture techniques, such as stress caused by the accumulation of gases and extreme humidity in the flasks, growth regulator concentrations stimulating bud formation or growth, number of subcultures, and the total duration for which the explant remains in vitro, can induce epigenetic alterations or true mutations (Krikorian et al, 1993; Karp 1994; Santos and Rodrigues 2004; Bairu et al. 2006). After acclimatization, the plantlets during I5 under the B spectrum showed normal development, indicating a temporary physiological effect. In the present study, no morphological variations were observed among the evaluated light treatments.

In conclusion, the use of the B spectrum for banana cultivation in a growth chamber or room may be used either exclusively or in combination with other techniques aimed at reducing the growth of the explant without compromising the material quality. This approach may provide more time to resolve operational problems or maintain an active germplasm bank in a CML.

Acknowledgments We thank ESALQ-USP for the infrastructure and technical support and João Geraldo Brancalion for figures and pictures.

\section{REFERENCES:}

Ahmad, I., Hussain, T., Ashraf, I., Nafes, M., Maryam., Rafay, M., Iqbal M (2013) Lethal Effects of Secondary Metabolites on Tc.Pdf. Amer Eur J Agric Environ Sci 13:539-547. https://doi.org/http://www.idosi.org/aejaes/jaes13(4)13/14.pdf

Bairu MW, Fennell CW, van Staden J (2006) The effect of plant growth regulators on somaclonal variation in Cavendish banana (Musa AAA cv. 'Zelig'). Scientia Horticulturae 108:347-351. https://doi.org/10.1016/j.scienta.2006.01.039

Biddington NL (1992) The influence of ethylene in plant tissue culture. Plant Growth Regulation 11:173-187. https://doi.org/10.1007/BF00024072

Buddendorf-Joosten JMC, Woltering EJ (1996) Controlling the gaseous composition in vitro - Description of a flow system and effects of the different gaseous components on in vitro growth of potato plantlets. Scientia Horticulturae 65:11-23. https://doi.org/10.1016/0304-4238(95)00857-8

De Carvalho V, Dos Santos DS, Nievola CC (2014) In vitro storage under slow growth and ex vitr acclimatization of the ornamental bromeliad Acanthostachys strobilacea. South African Journal of Botany 92:39-43. https://doi.org/10.1016/j.sajb.2014.01.011

Dutta Gupta S. AA (2017) Influence of LED Lighting on In Vitro Plant Regeneration and Associated Cellular Redox Balance. In: Light Emitting Diodes for Agriculture: Smart Lighting, Springer. pp 273-303

Gopal J, Chauhan NS (2010) Slow Growth In Vitro Conservation of Potato Germplasm at Low Temperature. Potato Research 53:141-149. https://doi.org/10.1007/s11540-010-9158-x

Kamińska M, Skrzypek E, Wilmowicz E, et al (2016) Effect of light conditions and ABA on cold storage and poststorage propagation of Taraxacum pieninicum. Plant Cell, Tissue and Organ Culture 127:25-34

Karp A (1994) Origins, Causes and Uses of Variation in Plant Tissue Cultures. Plant Cell and Tissue Culture 139151. https://doi.org/10.1007/978-94-017-2681-8_6

Kaur D, Ogra RK, Bhattacharya A, Sood A (2012) Changes in sugar levels during slow growth of Dendrocalamus hamiltonii somatic embryos due to liquid paraffin overlay. In Vitro Cellular and Developmental Biology Plant 48:120-126. https://doi.org/10.1007/s11627-011-9392-1

Krikorian, A.D., Irrizarry, H., Cronauer, S., Rivera E (1993) Clonal fidelity and variation in plantain (Musa AAB) regenerated from vegetative stem and floral axis tips in vitro. Annals of Botany 71:519-535

Manivannan A, Soundararajan P, Halimah N, et al (2015) Blue LED light enhances growth, phytochemical contents, 
and antioxidant enzyme activities of Rehmannia glutinosa cultured in vitro. Horticulture Environment and Biotechnology 56:105-113. https://doi.org/10.1007/s13580-015-0114-1

Marota WM, Otoni WC, Carnelossi M, et al (2001) Rhizogenesis in in vitro shoot cultures of passion fruit (Passiflora edulis f. flavicarpa Deg.) is affected by ethylene precursor and by inhibitors. International Journal of Horticultural Science 7:. https://doi.org/10.31421/ijhs/7/1/247

Murashige, T.; Skoog, F. (1962) A revised medium for rapid growth and bioassays with tobacco tissue cultures. Physiologia Plantarum 15:473-497

Nhut DT, Hong LTA, Watanabe H, et al (2002) Growth of banana plantlets cultured in vitro under red and blue light-emitting diode (LED) irradiation source. Acta Horticulturae 575:117-124. https://doi.org/10.17660/ActaHortic.2002.575.10

Oliveira RP de, Silva S de O e, Silva KM da, Silveira DG (2000) In vitro conservation of diploid banana accessions. Scientia Agricola 57:245-249. https://doi.org/10.1590/s0103-90162000000200008

Panis B, Nagel M, den Houwe I Van (2020) Challenges and prospects for the conservation of crop genetic resources in field genebanks, in in vitro collections and/or in liquid nitrogen. Plants 9:1-22. https://doi.org/10.3390/plants9121634

Pimenta M, Ribeiro C, Soares C, et al (2013) Ethylene synthesis inhibition effects on oxidative stress and in vitro conservation of Lippia filifolia (Verbenaceae). Brazilian Journal of Biology 73:617-621. https://doi.org/10.1590/s1519-69842013000300020

Rodrigues, P.H.V., Tulmann Neto, A., Cassieri Neto, P., Mendes BMJ (1998) Influence of the number of subcultures on somoclonal variation in micropropagated Nanicão (Musa spp., AAA group). Acta Hortic 490:469-473. https://doi.org/https://doi.org/10.17660/ActaHortic.1998.490.49

Rodrigues PHV, Arruda F, Forti VA (2018) Slow-grown in vitro conservation of Heliconia champneiana cv. Splash under different light spectra. Scientia Agricola 75:163-166. https://doi.org/10.1590/1678-992x-2016-0394

Santos CCC dos, Rodrigues PHV (2004) Variação somaclonal em mudas micropropagadas de bananeira, cultivar Pacovan. Bragantia 63:201-205. https://doi.org/10.1590/s0006-87052004000200005

Thakur S, Tiwari KL, Jadhav SK (2015) In vitro approaches for conservation of Asparagus racemosus Willd. In Vitro Cellular and Developmental Biology - Plant 51:619-625. https://doi.org/10.1007/s11627-015-9706-9

Van den houwe I, De Smet K, du Montcel HT, Swennen R (1995) Variability in storage potential of banana shoot cultures under medium term storage conditions. Plant Cell, Tissue and Organ Culture 42:269-274. https://doi.org/10.1007/BF00029998

Watt MP, Thokoane NL, Mycock D, Blakeway F (2000) In vitro storage of Eucalyptus grandis germplasm under minimal growth conditions. Plant Cell, Tissue and Organ Culture 61:161-164. https://doi.org/10.1023/A:1006447506869 


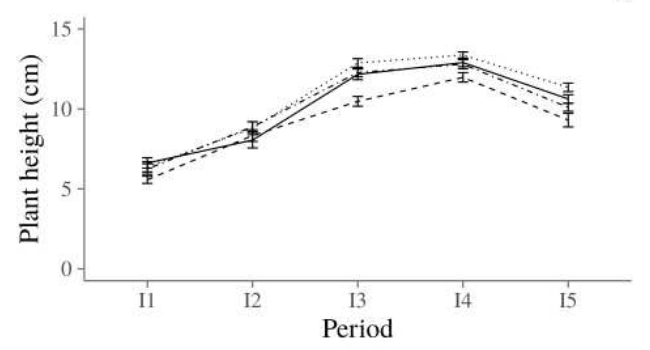

$\mathrm{c}$
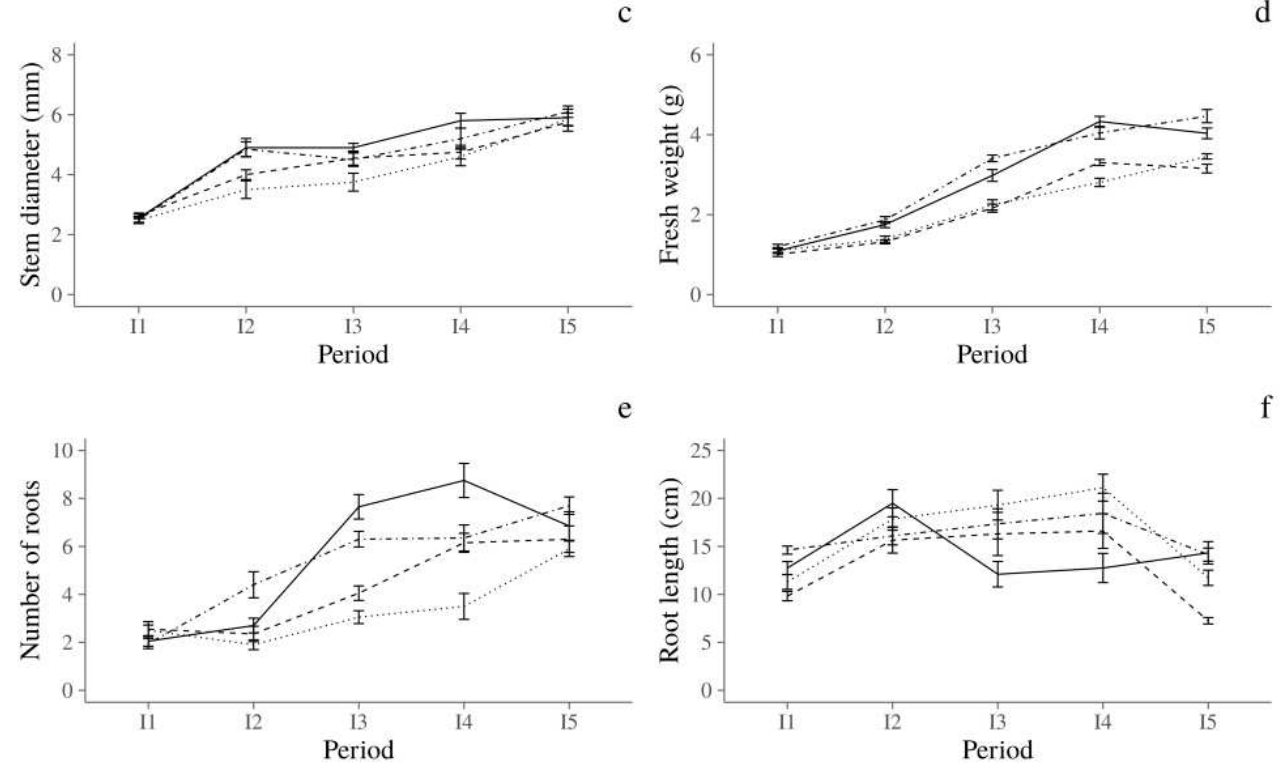

g
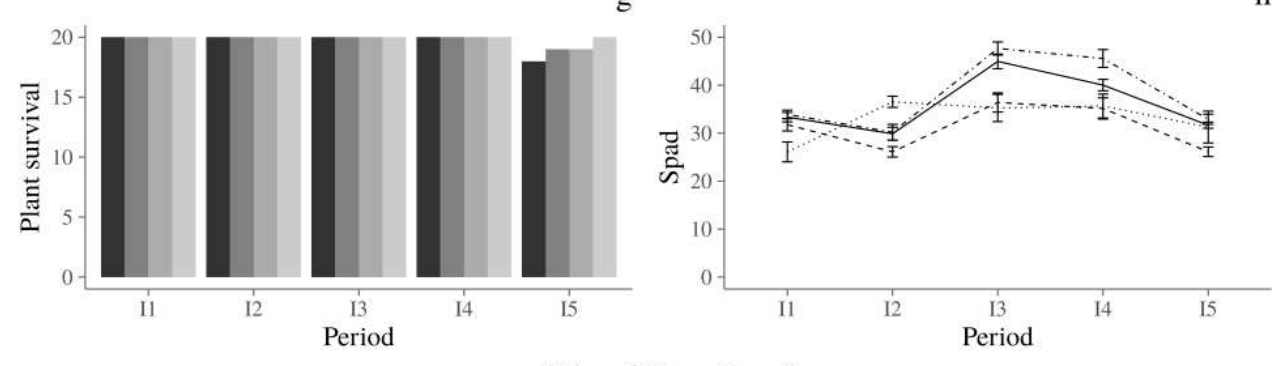

$-\mathrm{CW} \cdots \mathrm{R} 2 \mathrm{~B} \cdots \mathrm{R} \cdots \mathrm{B}$

Figure 1- Plantlets in SGS in different LS. Evaluation of banana shoots from cv. Prata Catarina in SGS for five periods of time in different LS. (a) Plant height-cm, (b) Number of leaves, (c) Stem diameter-mm, (d) Fresh weight-g, (e) Number of roots, (f) Root length-cm, (g) Plant survival and (h) SPAD. CW (Control White), R2B (70\% Red + 30\% Blue), R (100\% Red) and B (100\% Blue). 

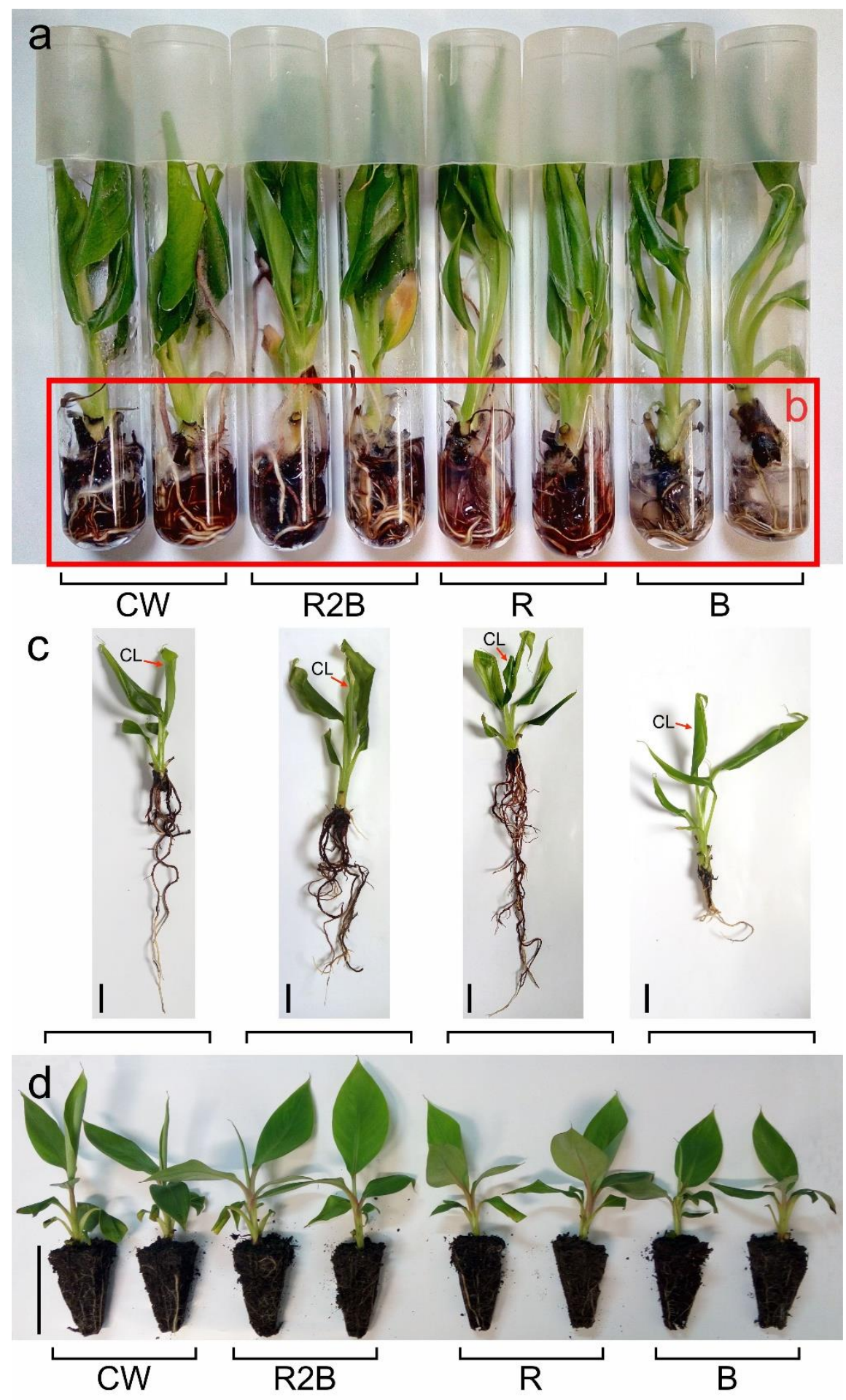

Figure 2- (a) Plantlets at different LS in SGS after 140 days (I5). (b) Detail the root plantlets in culture media in I5. (c) I5 Plantlets before acclimatization. (d) Acclimatized plantlets after four weeks. CL (cigar leaf), CW (Control White), R2B (70\% Red + 30\% Blue), R (100\% Red) and B (100\% Blue). Barr (c) $=1.5 \mathrm{~cm}$, Barr (d) $=6.0 \mathrm{~cm}$ 
a

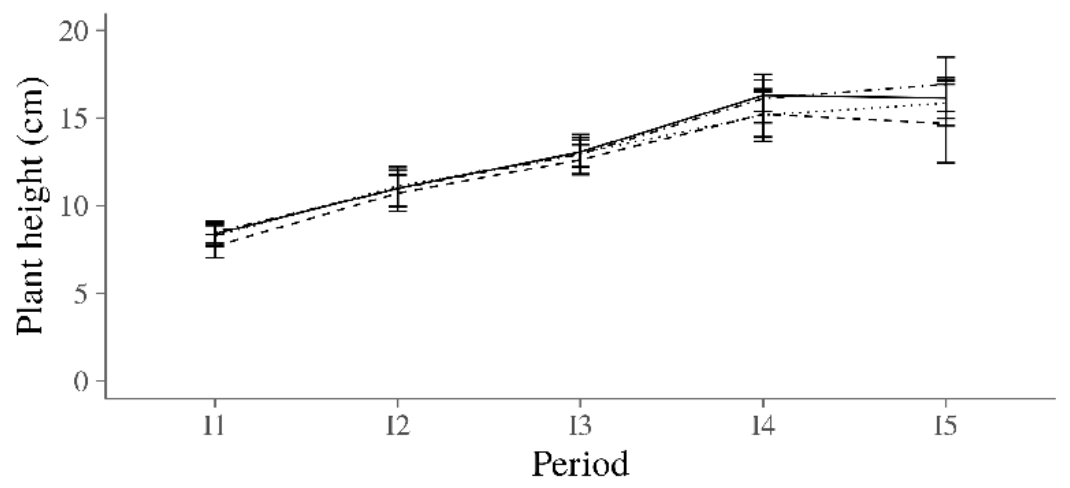

b

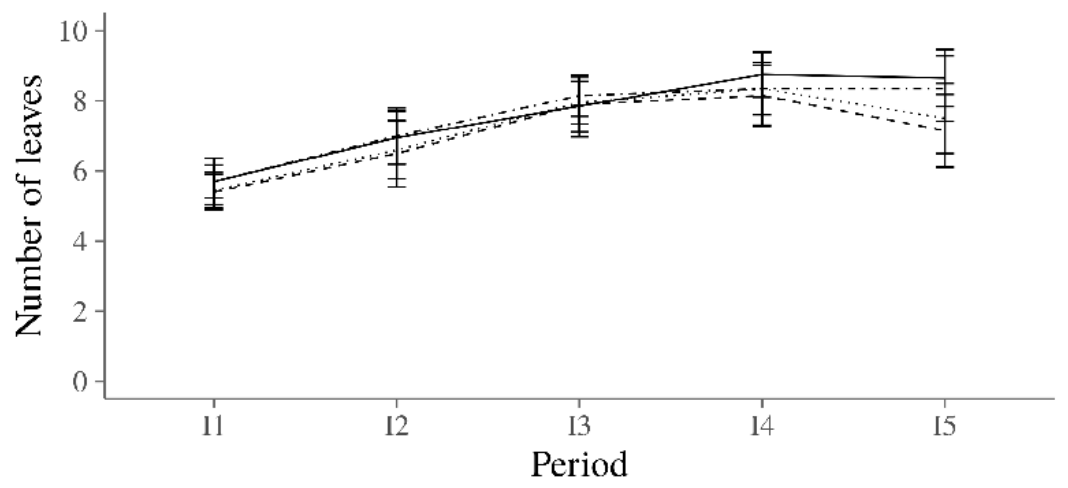

$\mathrm{c}$

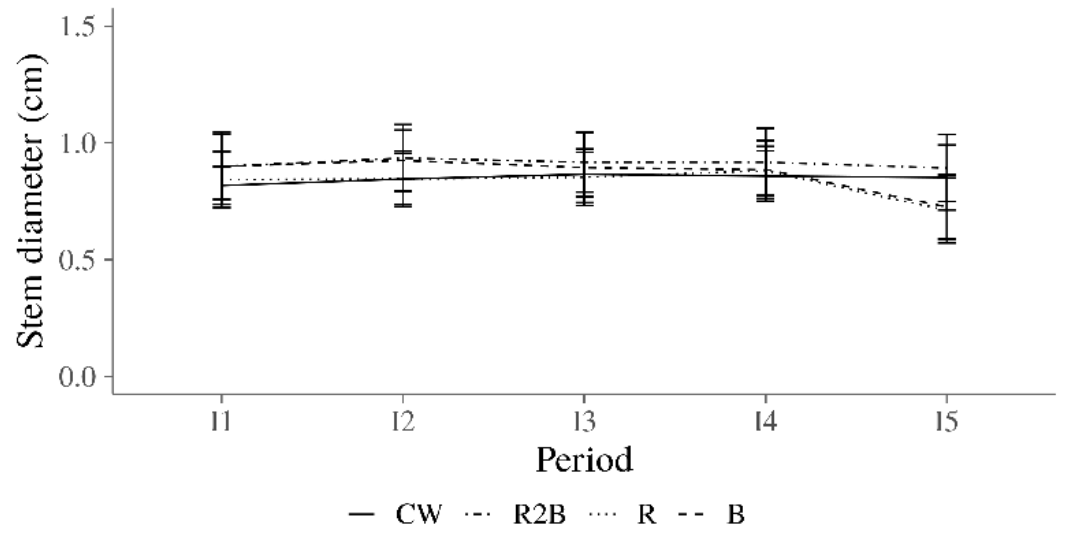

284 Figure 3- Evaluated banana plantlets cv. Prata Catarina in SGS for five periods after four weeks of acclimatization. (a) Plant height-cm, (b) Number of leaves, (c) Stem diameter-cm. 